\title{
Midterm Outcomes and Prognostic Factors of Patients Treated Using Microballoon-Occluded Transarterial Chemoembolization with Miriplatin: A Retrospective Study of 37 Cases
}

1) Department of Radiology, Kyushu University Beppu Hospital, Japan

2) Department of Radiology, Beppu Medical Center, Japan

3) Department of Internal Medicine, Beppu Medical Center, Japan

4) Department of Surgery, Kyushu University Beppu Hospital, Japan

5) Department of Clinical Radiology, Graduate School of Medical Sciences, Kyushu University, Japan

Masakazu Hirakawa ${ }^{122}$, Torahiko Yamanouchi ${ }^{2)}$, Satoru Tsuruta ${ }^{3)}$, Akihiro Inoue ${ }^{2)}$, Hidenari Hirata ${ }^{1)}$, Keiji Matsumoto ${ }^{1)}$, Katsumi Sakamoto ${ }^{1)}$, Hironori Sakai ${ }^{3)}$, Koshi Mimori ${ }^{4)}$, Hiroshi Honda ${ }^{5}$

Abstract

Purpose: This study aimed to retrospectively evaluate the overall survival and prognostic factors of patients treated using microballoon-occluded transarterial chemoembolization (B-TACE) with miriplatin for hepatocellular carcinoma (HCC).

Materials and Methods: Thirty-seven patients (23 men and 14 women; mean age, 74.1 years; Barcelona Clinic Liver Cancer stage A:21, B:10, C:6; first TACE, 17) treated using B-TACE with miriplatin were retrospectively analyzed. Overall survival and progression-free survival were analyzed using Kaplan-Meier methods, and a multivariate analysis was performed to identify prognostic factors. Side effects were analyzed on the basis of the National Cancer Institute's Common Terminology Criteria for Adverse Events (ver. 4.0).

Results: The 1-, 2-, and 3-year survival rates were $89.2 \%$ (95\% confidence interval [CI], 74.5-95.9\%), $67.3 \%$ (95\% CI, 50.7-80.4\%), and 60.9\% (95\% CI, 44.1-75.4\%), respectively. The median survival time was 3.6 years. The median progression-free survival time was 8 months. Balloon increase (increased tumor stain under balloon occlusion; hazard ratio, 3.17; 95\% CI, 1.135-11.201; $\mathrm{P}=0.027$ ) was the only factor significantly associated with overall survival on the multivariate analysis. No deaths occurred, but grade 2 cholecystitis requiring conservative treatment developed in 2 patients (4.8\%). No adverse events over grade 3 occurred.

Conclusion: B-TACE with miriplatin was associated with comparable tumor control and overall survival without severe adverse events in patients with HCC. Balloon increase was the only factor significantly associated with overall survival.

Key words: hepatocellular carcinoma, microballoon-occluded transarterial chemoembolization, miriplatin, survival

(Interventional Radiology 2018; 3: 97-109)

Received: February 16, 2018. Accepted: June 29, 2018.

doi: 10.22575/interventionalradiology.2018-0001

Correspondence Author: Masakazu Hirakawa. E-mail: mahira@radiol.med.kyushu-u.ac.jp 


\section{INTRODUCTION}

Hepatocellular carcinoma (HCC) is one of the most common malignancies worldwide. The incidence of HCC is relatively high in east and southeast Asia [1], where there are high incidences of chronic hepatitis $\mathrm{B}$ and $\mathrm{C}$ infections. Curative therapies including resection, liver transplantation, and percutaneous ablations, such as radiofrequency ablation (RFA), are applicable to only $30-40 \%$ of patients with HCC [2]. Other patients with HCC typically undergo palliative treatments because of advanced tumor stage or poor hepatic functional reserve. Transarterial chemoembolization (TACE) has been widely used for the treatment of Barcelona Clinic Liver Cancer (BCLC) stage B HCC, which is defined as an intermediate-stage disease [3-5]. TACE has been recognized as an effective palliative treatment option for patients with HCC that is unresectable or cannot be treated with percutaneous interventions, with proven survival improvement in selected patients [6-9]. Since 2011, a microballoon catheter (Attendant, Terumo Clinical Supply, Gifu, Japan) has been available for selective TACE for HCC [10]. Microballoonoccluded transarterial chemoembolization (B-TACE) was shown to induce dense iodized oil accumulation in HCC nodules. Under microballoon occlusion, this may be due to the hemodynamic change in the treated liver segment, forceful retrograde injection of embolic agents into the collateral vessels, and prevention of embolic agent migration into other hepatic arteries [11].

Miriplatin (Miripla; Dainippon Sumitomo Pharma, Osaka, Japan) is a lipophilic platinum complex that is theoretically a good candidate as an anticancer agent in TACE because of its lipophilicity and sustained release [12, 13]. However, in clinical practice, many radiologists have pointed out that the injection of a miriplatin-lipiodol suspension requires an unusually high pressure through a microcatheter, and that it has a lower local control effect for HCCs than do other anticancer agents because of its high viscosity [14, 15]. Recently, some studies reported that relatively good local control could be obtained after B-TACE with miriplatin without a significant increase in adverse effects than that after conventional-TACE (C-TACE) using miriplatin $[16,17]$. To the best of our knowledge, only one previous report has documented the survival rate following B-TACE with miriplatin [18]. The aim of this retrospective study was to analyze patients' midterm survival after B-TACE with miriplatin for HCCs and to identify the prognostic factors.

\section{MATERIALS and METHODS}

This retrospective study was performed with the approval of our institutional review board, and informed consent was obtained from all patients.

\section{Patients}

In our institutions, TACE was indicated for patients when percutaneous RFA, percutaneous ethanol injection therapy (PEIT), or surgical resection was not indicated. The contraindications to RFA or PEIT were as follows: lesion larger than $3 \mathrm{~cm}$; lesions adjacent to the gallbladder, stomach, common biliary duct, or colon; and lesions in a difficult location for needle placement. The treatment strategy for HCC was determined by both the radiologist and hepatologists in consensus. The medical records and radiological images of 51 consecutive patients who underwent B-TACE with miriplatin for unresectable HCCs at our institution between November 2012 and January 2014 were reviewed. Six patients treated using B-TACE with epirubicin (Nippon Kayaku, Tokyo, Japan), 3 patients with target HCCs treated with RFA within 3 months after B-TACE, and 5 patients without follow-up were excluded. Consequently, this study included 37 patients (23 men and 14 women; mean age, 74.1 years) with HCCs treated using B-TACE with miriplatin. The preprocedural diagnosis of HCC was established on the basis of the findings of contrast ( $370 \mathrm{mg} \mathrm{I} / \mathrm{ml}$ iopamidol, Iopamiron 370; Bayer Schering Pharma, Osaka, Japan; Omnipaque 350, Daiichi-Sankyo, Tokyo, Japan)-enhanced dynamic computed tomography (CT) (Aquilion 64; Toshiba, Tokyo, Japan or SOMATOM Sensation 64-slice Configuration, Siemens, Germany ) imaging and/or gadolinium-ethoxybenzyldiethylenetriamine pentaacetic acid (Gd-EOB-DTPA; Primovist, Bayer Schering Pharma)-enhanced magnetic resonance imaging (MRI, MAGNETOM ESSENZA 1.5T; Siemens) showing a characteristic homogeneous or mosaic-like nodular enhancement in the arterial phase and wash-out in the delayed phase. The patient characteristics before TACE are summarized in Table $\mathbf{1 .}$

\section{B-TACE procedure}

A $4 \mathrm{~F}$ or $5 \mathrm{~F}$ hook-shaped guiding catheter was placed in the celiac or common hepatic artery. The microballoon catheter (LOGOS; 1.8 Fr tip, PIOLAX, Tokyo, Japan or Attendant LP 3.0 Fr tip or Nexus 1.9 Fr tip, Terumo Clinical Supply, Gifu, Japan) was placed in the segmental or subsegmental artery of the hepatic artery via the guiding catheter to perform B-TACE. The maximum balloon diameter was 4 $\mathrm{mm}$, and the microballoon catheter was introduced over a 0.014-inch guide wire (Labyrinth; PIOLAX, or GT wire, Terumo Clinical Supply). The balloon was inflated to a diameter 5-10\% larger than that of the occluded artery. Under microballoon occlusion, selective angiography was performed, and the feeding arteries and tumor stains of the target lesions were identified. Before treatment, CT was not performed during angiography.

The miriplatin-lipiodol suspension was prepared by dissolving $60 \mathrm{mg}$ miriplatin (maximum dose, $120 \mathrm{mg}$ ) in 3.5 $\mathrm{ml}$ lipiodol (maximum dose, $7 \mathrm{ml}$ ). The miriplatin-lipiodol suspension was warmed to $40^{\circ} \mathrm{C}[15,16]$ and immediately administered after balloon inflation. The miriplatin-lipiodol suspension was continuously infused under balloon occlusion until the HCC nodule was filled with lipiodol, or until the portal venous branches or intersegmental anastomoses of 
Table 1. Patient characteristics

\begin{tabular}{|c|c|}
\hline & B-TACE $(n=37)$ \\
\hline Male/Female & $23 / 14$ \\
\hline Age (years old) & $74.1 \pm 9.02(59-87)$ \\
\hline ECOG score $(0 / 1 / 2 / 3)$ & $27 / 9 / 1 / 0$ \\
\hline Child-Pugh class $(\mathrm{A} / \mathrm{B} / \mathrm{C})$ & $25 / 12 / 0$ \\
\hline $\begin{array}{l}\text { Etiology } \\
\text { (HBV/HCV/NBNC) }\end{array}$ & $6 / 15 / 16$ \\
\hline BCLC stage $(A / B / C)$ & $21 / 10 / / 6$ \\
\hline Main tumor size $(\mathrm{cm})$ & $\begin{array}{l}2.8 \pm 1.3(1.3-6) \\
\text { Median } 2.6\end{array}$ \\
\hline $\begin{array}{l}\text { Number of tumors } \\
(1 / 2 / 3 / \text { Multiple })\end{array}$ & $21 / 7 / 3 / 6$ \\
\hline PVTT (None/Branch) & $32 / 5$ \\
\hline & $1478 \pm 5780$ \\
\hline Des-y-carboxyprothrombin (AU/I) & $\begin{array}{l}\text { Median } 55.0 \\
(19-13378)\end{array}$ \\
\hline & $183 \pm 405$ \\
\hline $\operatorname{AFP}(\mathrm{U} / \mathrm{ml})$ & $\begin{array}{l}\text { Median } 10.6 \\
(32.4-28400)\end{array}$ \\
\hline Previous TACE/RFA/Ope & $19 / 4 / 4$ \\
\hline $\begin{array}{l}\text { Balloon increase/decrease } \\
\text { Treatment area }\end{array}$ & $15 / 22$ \\
\hline $\begin{array}{l}\text { Subsegmental/Segmental/Lobe/ } \\
\text { Whole liver }\end{array}$ & $5 / 26 / 2 / 2$ \\
\hline $\begin{array}{l}\text { Treated vessels } \\
\text { Subsegmental/Segmental }\end{array}$ & $10 / 27$ \\
\hline $\begin{array}{l}\text { Dose of administrated miriplatin } \\
\text { (mg) }\end{array}$ & $\begin{array}{l}55.6 \pm 23.7(20-120) \\
\text { Median } 60\end{array}$ \\
\hline Dose of lipiodol (ml) & $\begin{array}{l}3.1 \pm 1.2(1.2-7) \\
\text { Median } 3.5\end{array}$ \\
\hline
\end{tabular}

Mean \pm SD (minimum-maximum).

Note: B-TACE, balloon-occluded transcatheter arterial chemoembolization with

miriplatin; ECOG, Eastern Cooperative Oncology Group Performance Status;

$\mathrm{HBV}$, hepatitis B virus; HCV, hepatitis C virus; NBNC, no HBV and no HCV;

BCLC, Barcelona Clinic Liver Cancer; Tumor size, maximum diameter of the

tumor; PVTT (Branch), portal vein tumor thrombosis in the 2nd or lower branch;

AFP, a-fetoprotein; RFA, radiofrequency ablation; Ope, hepatic resection

the hepatic artery were beginning to be filled with lipiodol. Then, fragmented gelatin particles (Gelpart; $1 \mathrm{~mm}$ in diameter, Nippon Kayaku), which were fragmented into smaller sizes by pumping between 2 syringes 10 times by using a three-way stopcock, were infused until they filled the arterial branches beyond the catheter tip. In all cases included in this study, the balloon was inflated from the start of miriplatin-lipiodol suspension infusion to the end of gelatin particle infusion, regardless of the change in the tumor stain under balloon occlusion.

In cases with multiple HCCs in the both hepatic lobe, the doses of the miriplatin-lipiodol suspension and gelatin 

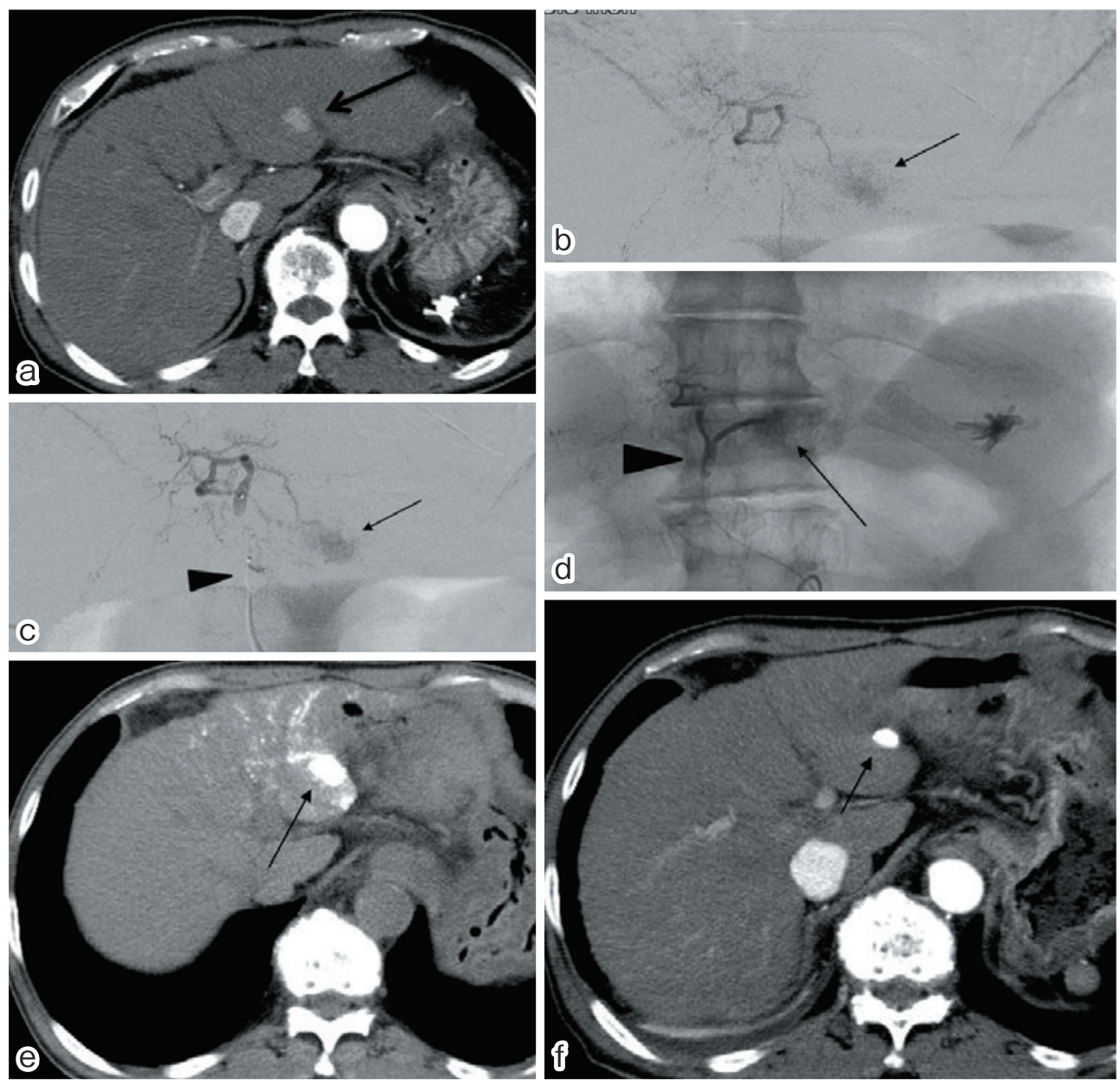

Figure 1. Hepatocellular carcinoma (diameter, $23 \mathrm{~mm}$ ) at the left lateral segment in a 71-year-old man with hepatitis $\mathrm{C}$ who underwent B-TACE with miriplatin. (a) Arterial-phase image from dynamic contrast-enhanced computed tomography (CT) acquired before treatment shows a well-enhanced nodular lesion (arrow). (b) Left hepatic arteriogram without balloon occlusion shows a tumor stain (arrow). (c) Left hepatic arteriogram with balloon occlusion shows that the tumor stain has higher enhancement than that without balloon occlusion. (c) This was defined as belonging in the balloon increase group. (d) Digital fluorography performed during infusion of the miriplatin-lipiodol suspension under balloon occlusion (arrow head, B-TACE) via the left hepatic artery shows that the miriplatin-lipiodol suspension is distributed into the HCC nodule (arrow). (e) Unenhanced CT acquired 2 weeks after treatment shows that the accumulated iodized oil has remained, and no viable component has emerged (arrow). (f) Arterial-phase image from contrast-enhanced CT acquired 6 months after treatment shows that the tumor size has decreased, and there is no local tumor recurrence (arrow).

sponge were determined on the basis of tumor size, degree of lipiodol deposition in the target lesions compared to that of tumor stains on hepatic angiography before B-TACE, and degree of hepatic reserve. Lipiodol deposition in the target HCCs was not checked on CT-like images after treatment.

\section{Assessments}

\section{Assessment of angiography findings}

Two experienced radiologists, who were blinded to the patients' information, retrospectively reviewed the tumor stain of the largest HCC obtained by selective angiography with and without balloon occlusion of the tumor feeders. All the largest tumors were classified into either of the follow- ing groups: balloon increase group, in which the tumor stain showed increased enhancement on selective angiography with balloon occlusion than in the one without balloon occlusion (Fig. 1); and the balloon decrease group, in which the tumor stain showed decreased enhancement on selective angiography with balloon occlusion than in the one without balloon occlusion or almost the same enhancement on selective angiography with and without balloon occlusion (Fig. 2). This assessment was a subjective comparison of tumor stains. In case of disagreements, the 2 radiologists discussed and determined the balloon increase or decrease. 

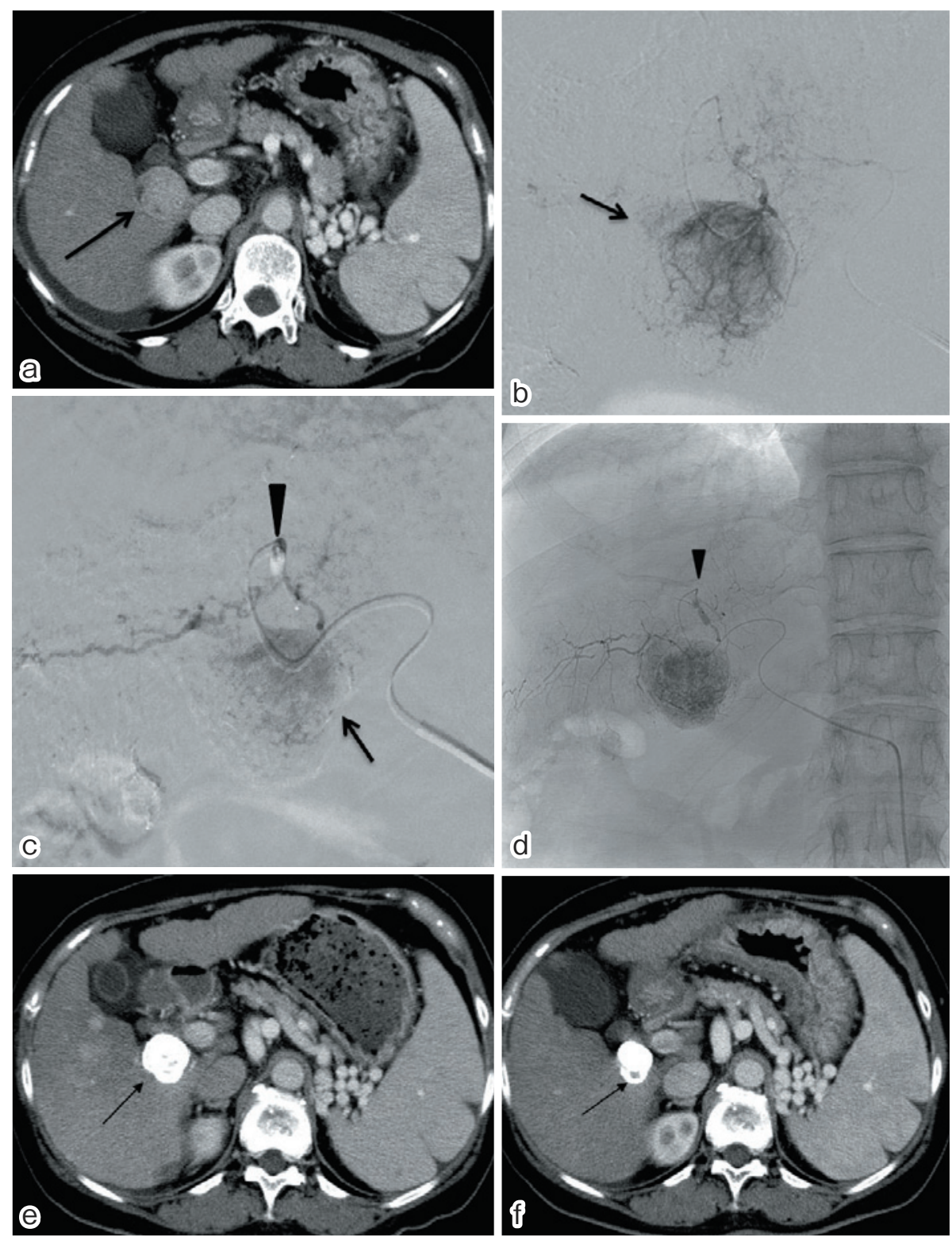

Figure 2. Hepatocellular carcinoma (diameter, $38 \mathrm{~mm}$ ) at hepatic segment $\mathrm{I}$ in a 60 -year-old woman with hepatitis B who underwent B-TACE with miriplatin. (a) Arterial-phase image from dynamic contrast-enhanced computed tomography (CT) before treatment shows a well-enhanced nodular lesion located near the inferior vena cava (arrow). (b) Selective arteriogram of A1 without balloon occlusion shows a fine tumor stain. (c) Selective arteriogram of A1 with balloon (arrow head) occlusion shows a decreased tumor stain. This was defined as a balloon decrease case. (d) Digital fluorography performed during infusion of a miriplatin-lipiodol suspension under balloon (arrow head) occlusion (B-TACE) shows good lipiodol accumulation in the HCC nodule. (e) Arterial-phase image from contrast-enhanced CT acquired 2 weeks after treatment shows that the accumulated iodized oil has remained, and no viable component has emerged (arrow). (f) Arterial-phase image from contrast-enhanced CT acquired 3 months after treatment shows that the tumor size has decreased, but lipiodol has washed out. This was diagnosed as local tumor recurrence (arrow).

\section{Evaluation of tumor progression}

Tumor progression, including local recurrence and new lesions after B-TACE, was evaluated using dynamic CT and/ or EOB-enhanced MRI 1-3 months after B-TACE. Local recurrence was considered present when an early enhancing tumor without iodized oil accumulation was observed in or adjacent to the treated tumors. Two radiologists (with 8 and 20 years of experience in radiology), who were blinded to the TACE methods, assessed tumor progression by consensus.

\section{Toxicity evaluation}

Treatment-related toxicity was assessed using the National 


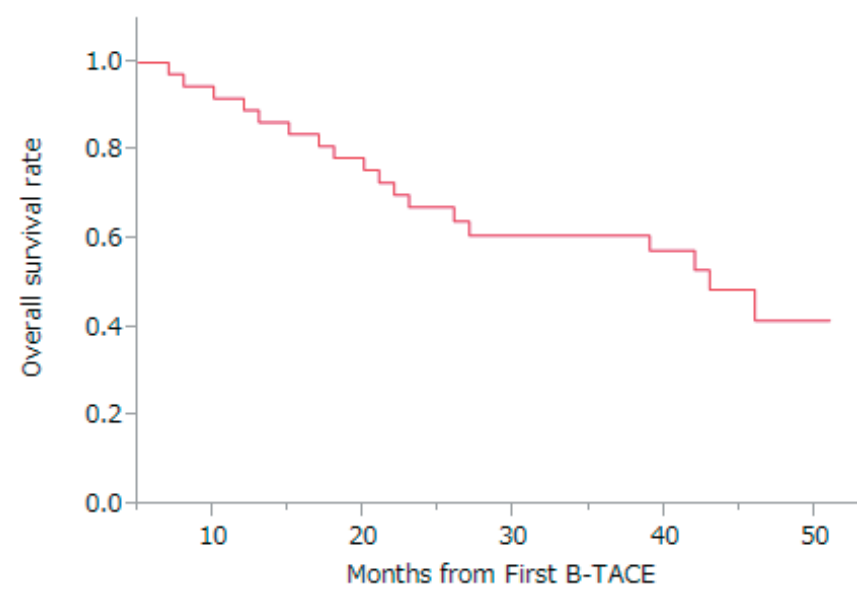

Figure 3. The cumulative survival rate showing overall survival in all patients undergoing BTACE with miriplatin. The median survival time is 3.6 years (43 months). The 1-, 2-, and 3-year survival rates are $89.2 \%(95 \%$ CI, 74.5-95.9\%), $67.3 \%$ (95\% CI, 50.7-80.4\%), and $60.9 \%(95 \%$ CI, 44.1-75.4\%), respectively.

Cancer Institute's Common Terminology Criteria for Adverse Events (CTCAE ver. 4.0). Adverse events were evaluated as the maximum change in grade within the 2 weeks after TACE.

\section{Treatment for recurrences after initial B-TACE}

When local recurrence or new lesions were detected on follow-up CT/MRI, on-demand TACE was performed in most cases unless the liver function had deteriorated to Child-Pugh class $\mathrm{C}$ and a portal venous thrombus was not seen in the lobar branch or main trunk. In most cases, when the recurrent lesions were a relatively small number of nodules, B-TACE with miriplatin was performed repeatedly, and when multiple lesions requiring a wide treatment area were present, drug-eluting bead (DEB)-TACE was administered. Sorafenib treatment was administered when the definition of TACE failure/refractoriness proposed by the Japan Society of Hepatology and Liver Cancer Study Group of Japan was satisfied after repeated on-demand TACE [19]. RFA was performed when the size and number of recurrent nodules were limited to within $3 \mathrm{~cm}$ and within $3 \mathrm{HCC}$ nodules, respectively, and when the recurrent nodules were safe locations for needle placement.

\section{Assessment of vascular damage}

Two experienced abdominal and interventional radiologists, who were blinded to the patients' information, retrospectively evaluated the damage to the treated arteries of the largest tumors on celiac or common hepatic angiograms in 32 recurrent cases by using a three-grade scale (1, no or slight wall irregularity; 2, overt stenosis; or 3, occlusion). Grades 2 and 3 were considered to indicate significant hepatic arterial damage (HAD) [20]. We evaluated the treated arteries of the largest tumors on celiac or common hepatic angiograms acquired during the final angiography during BTACE in 21 patients treated with only repeated B-TACE. In 11 patients treated with DEB-TACE, the treated arteries of the largest tumors on celiac or common hepatic angiograms acquired during DEB-TACE after the final B-TACE were evaluated to exclude the effect of DEB-TACE on vascular damage caused by B-TACE.

\section{Statistical analysis}

Overall survival and progression-free survival rates were calculated using the Kaplan-Meier method. Prognostic factors affecting overall survival and progression-free survival rates were analyzed using univariate and multivariate analyses with the Cox proportional hazard analysis. The following factors were assessed: gender, age, Child-Pugh classification, Eastern Cooperative Oncology Group Performance Status, serum $\alpha$-fetoprotein (AFP) level, serum des- $\gamma$ carboxyprothrombin level, portal vein tumor thrombosis (PVTT) in the 2nd or lower branch, BCLC stage, previous C-TACE, maximum tumor diameter, tumor multiplicity, and change in the largest tumor stain on selective angiography with and without balloon occlusion. $\mathrm{P}<0.05$ was considered significant. All variables with $\mathrm{P}<0.05$ on the univariate analysis were subjected to the multivariate analysis. The follow-up time was defined as the interval between the date of the first B-TACE treatment and death or the last visit to the outpatient clinic, until March 31, 2017. The results of the multivariate analyses are expressed as hazard ratios (HRs) with the corresponding 95\% confidence intervals (CIs) and P values. Statistical analyses were performed using JMP (version 11; SAS Institute, Cary, NC).

\section{RESULTS}

Patient characteristics and treatment results are summarized in Table $\mathbf{1}$.

The mean follow-up duration was 31.4 months (range, 645; median, 30 months). Of the 37 patients, 14 died at the time of analysis because of the progression of HCC $(n=3)$, liver failure $(n=9)$, ileus $(n=1)$, and mesothelioma $(n=$ 


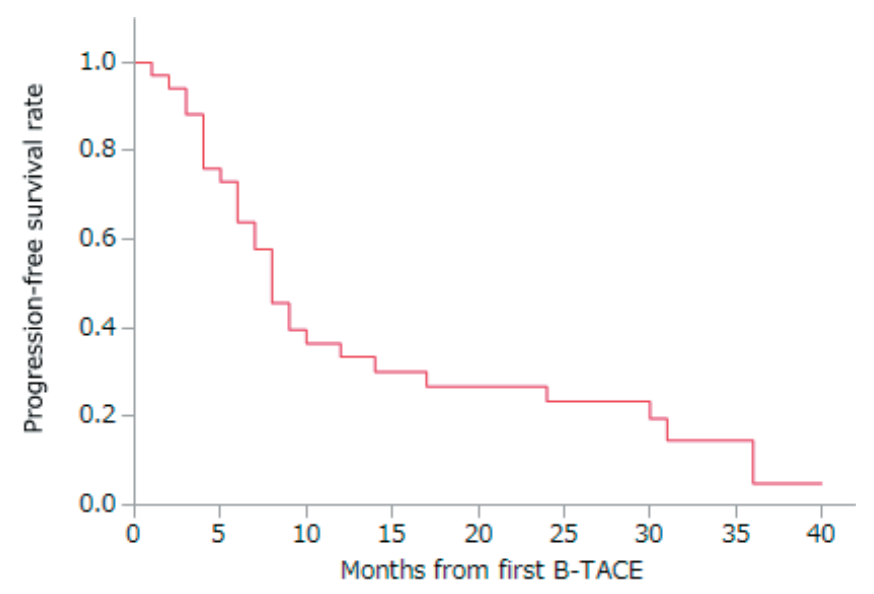

Figure 4. The cumulative survival rate showing progression-free survival in all patients undergoing B-TACE with miriplatin. The median progression-free survival time is 8 months. The 1-, 2-, and 3-year progression-free survival rates are $33.5 \%, 21.3 \%$, and $4.4 \%$, respectively.

1). The 1-, 2-, and 3-year survival rates were $89.2 \%(95 \%$ CI, $74.5-95.9 \%), 67.3 \%$ (95\% CI, 50.7-80.4\%), and $60.9 \%$ (95\% CI, 44.1-75.4\%), respectively (Fig. 3). The median survival time was 3.6 years. The median progression-free survival time was 8 months (Fig. 4). The pattern of disease progression was locoregional recurrence in 26 patients $(81.3 \%)$ and a new lesion in the liver in 6 patients $(18.7 \%)$. All 32 patients with disease progression received on-demand B-TACE with miriplatin (number of B-TACE procedures, 111). Eleven of 32 patients with disease progression received DEB-TACE (number of DEB-TACE procedures, 1-3 per patient), and 5 patients with new lesions received local ablation, including RFA or PEIT (number of RFA or PEIT procedures, 1-2 per patient). Four patients received sorafenib treatment.

Balloon increase (HR, 3.17; 95\% CI, 1.135-11.201; $\mathrm{P}=$ 0.027 ) was the only factor significantly associated with overall survival on the multivariate analysis (Table 2). Balloon increase, absence of PVTT, absence of previous TACE, and maximum tumor size smaller than $2 \mathrm{~cm}$ were significantly associated with progression-free survival on the univariate analysis, but no prognostic factor was significantly associated with progression-free survival on the multivariate analysis (Table 3).

\section{Vascular damage caused by B-TACE with miriplatin}

After B-TACE (mean, $2.6 \pm 1.3$; median, 3; range, 1-5 sessions), significant HAD occurred in 7 of 32 treated hepatic arteries (21.9\%). HAD was interpreted as being grades 1,2 , and 3 in $25(78.1 \%), 6(18.8 \%)$, and 1 (3.1\%), respectively (Fig. 5 and 6). All of the patients with significant HAD had received 3 or more B-TACE sessions.

\section{Adverse events}

The results regarding the adverse events of the first BTACE classified according to the CTCAE ver. 4.0 are summarized in Table 4. Cholecystitis of grade 2 developed in 2 patients. The cholecystitis improved with conservative treat- ment without cholecystectomy. In 2 patients, elevated aspartate aminotransferase and alanine aminotransferase levels of grade 2 were seen, but these recovered to the baseline levels. In the present study, the other adverse events were all grade 1 , and no mortality related to B-TACE occurred.

\section{DISCUSSION}

Previous randomized controlled trials and meta-analyses have confirmed the survival benefit of TACE [21, 22]. TACE is recommended as the standard treatment for BCLC stage B HCC [3]. Recent studies reported that B-TACE with miriplatin induced a high local control effect for target HCCs $[16,17]$. Irie et al. examined the mechanisms underlying the effects of B-TACE. Inflation of the tip of the balloon catheter reduces the balloon-occluded arterial stump pressure (BOASP) at the embolization portion while maintaining distal arterial blood flow. In these cases with reduced BOASP, lipiodol and embolic agents could be injected under balloon occlusion more effectively than with C-TACE because of the decreased pressure gradient between the occluded artery and the portal vein under balloon occlusion. Consequently, B-TACE induced denser lipiodol emulsion accumulation and a good local control effect in the HCC nodules $[11,17]$. Recent studies reported favorable predictors affecting the local control effect after B-TACE as follows: portal vein visualization during B-TACE, tumor on the subcapsular portion, successful subsegmental feeding artery embolization [23], single HCC, AFP level < 20 ng/ml [18], high CT value immediately after B-TACE [24], and enhanced tumor stain on CT during hepatic angiography under balloon occlusion [25]. In the present study, balloon increase, absence of PVTT, absence of previous C-TACE, and maximum tumor size smaller than $2 \mathrm{~cm}$ were significantly associated with progression-free survival on the univariate analysis, but none were significantly associated with progression-free survival on the multivariate analysis. In this study, balloon increase was a favorable prognostic factor for 
Interventional Radiology 2018; 3: 97-109

Table 2. Univariate and multivariate analyses for variables affecting overall survival after B-TACE

\begin{tabular}{|c|c|c|c|c|}
\hline \multicolumn{4}{|c|}{ Univariate } & \\
\hline \multicolumn{2}{|l|}{ Variable } & Adjusted HR $(95 \% \mathrm{Cl})$ & $p$ & \\
\hline \multirow[t]{2}{*}{ Gender } & Male & 1 & 0.2602 & \\
\hline & Female & $1.744(0.651-4.587)$ & & \\
\hline \multirow[t]{2}{*}{ Age } & $>75 y$ & 1 & 0.3960 & \\
\hline & $<75$ y & $1.533(0.596-4.089)$ & & \\
\hline \multirow[t]{2}{*}{ Child-Pugh class } & $A$ & 1 & 0.5888 & \\
\hline & B & $1.320(0.455-3.435)$ & & \\
\hline \multirow[t]{2}{*}{ Virus } & $\mathrm{HCV}$ & 1 & 0.730 & \\
\hline & Other & $1.1184(0.460-3.261)$ & & \\
\hline \multirow[t]{2}{*}{ ECOG PS } & 0 & 1 & 0.4971 & \\
\hline & more & $1.456(0.4588-3.985)$ & & \\
\hline \multirow[t]{2}{*}{ AFP } & $<40$ & 1 & 0.642 & \\
\hline & $>40$ & $1.257(0.460-3.220)$ & & \\
\hline \multirow[t]{2}{*}{$\mathrm{DCP}$} & $<40$ & 1 & 0.649 & \\
\hline & $>40$ & $1.256(0.4482-3.637)$ & & \\
\hline \multirow[t]{2}{*}{ Balloon change } & Increase & 1 & 0.027 & \\
\hline & Decrease & $3.170(1.135-11.201)$ & & \\
\hline \multirow[t]{2}{*}{ PVTT } & None & 1 & 0.139 & \\
\hline & Branch & $2.254(0.708-7.312)$ & & \\
\hline \multirow[t]{2}{*}{ BCLC } & $A$ & 1 & 0.628 & \\
\hline & $\mathrm{B}$ or $\mathrm{C}$ & $1.257(0.490-3.223)$ & & \\
\hline \multirow[t]{2}{*}{ Previous C-TACE } & None & 1 & 0.2934 & \\
\hline & & $1.374(0.647-4.824)$ & & \\
\hline \multirow[t]{2}{*}{ Max size } & $<2 \mathrm{~cm}$ & 1 & 0.664 & \\
\hline & $>2 \mathrm{~cm}$ & $1.153(0.471-3.916)$ & & \\
\hline \multirow[t]{3}{*}{ Tumor } & Number < & 1 & 0.3252 & \\
\hline & 3 & $1.724(0.549-4.622)$ & & \\
\hline & more & & & \\
\hline \multirow[t]{3}{*}{ Multivariate analysis } & Balloon & Increase & 1 & 0.027 \\
\hline & change & Decrease & 3.170 & \\
\hline & & & $(1.135-11.201)$ & \\
\hline
\end{tabular}

B-TACE, balloon-occluded transcatheter arterial chemoembolization with miriplatin; $\mathrm{HR}$, hazard ratio; $\mathrm{Cl}$, confidence interval; $\mathrm{HCV}$, hepatitis $\mathrm{C}$ virus; ECOG PS, Eastern Cooperative Oncology Group Performance Status; AFP, a-fetoprotein; DCP, des-y-carboxyprothrombin; PVTT (Branch), portal vein tumor thrombosis in the 2nd or lower branch; BCLC, Barcelona Clinic Liver Cancer; C-TACE, conventional transcatheter arterial chemoembolization with epirubicin; Tumor size, maximum diameter of the tumor 
Table 3. Univariate and multivariate analyses of variables affecting progression-free survival after B-TACE

\begin{tabular}{|c|c|c|c|c|c|}
\hline \multirow[b]{2}{*}{ Variable } & & \multicolumn{2}{|c|}{ Univariate analysis } & \multicolumn{2}{|c|}{ Multivariate analysis } \\
\hline & & $\begin{array}{l}\text { Adjusted HR (95\% } \\
\text { Cl) }\end{array}$ & $p$ & $\begin{array}{c}\text { Adjusted } \\
\text { HR (95\% } \\
\mathrm{Cl}) \\
\end{array}$ & $p$ \\
\hline \multirow[t]{2}{*}{ Gender } & Male & 1 & 0.212 & & \\
\hline & Female & $0.627(0.283-1.295)$ & & & \\
\hline \multirow[t]{2}{*}{ Age } & $>75 y$ & 1 & 0.112 & & \\
\hline & $<75 y$ & $0.566(0.275-1.141)$ & & & \\
\hline Child-Pugh & $A$ & 1 & 0.157 & & \\
\hline class & B & $1.787(0.789-3.825)$ & & & \\
\hline \multirow[t]{2}{*}{ Virus } & $\mathrm{HCV}$ & 1 & 0.815 & & \\
\hline & Other & $0.916(0.447-1.961)$ & & & \\
\hline \multirow[t]{2}{*}{ ECOG PS } & 0 & 1 & 0.742 & & \\
\hline & more & $1.141(0.497-2.405)$ & & & \\
\hline \multirow[t]{2}{*}{ AFP } & $<40$ & 1 & 0.763 & & \\
\hline & $>40$ & $1.121(0.519-2.291)$ & & & \\
\hline \multirow[t]{2}{*}{ DCP } & $<40$ & 1 & 0.904 & & \\
\hline & $>40$ & $1.044(0.495-2.112)$ & & & \\
\hline Balloon & Increase & 1 & 0.0146 & 1 & 0.1469 \\
\hline \multirow[t]{3}{*}{ change } & Decrease & $2.655(1.208-6.233)$ & & 1.904 & \\
\hline & & & & $(0.800-4.7$ & \\
\hline & & & & 85) & \\
\hline \multirow[t]{4}{*}{ PVTT } & None & 1 & 0.027 & 1 & 0.1165 \\
\hline & Branch & 3.674 (1.179-9.669) & & 2.536 & \\
\hline & & & & (0.7765-7. & \\
\hline & & & & 277) & \\
\hline
\end{tabular}

\begin{tabular}{|c|c|c|c|c|c|}
\hline \multirow[b]{2}{*}{ Variable } & & \multicolumn{2}{|c|}{ Univariate analysis } & \multicolumn{2}{|c|}{ Multivariate analysis } \\
\hline & & $\begin{array}{l}\text { Adjusted HR }(95 \% \\
\qquad \mathrm{Cl})\end{array}$ & $p$ & $\begin{array}{c}\text { Adjusted } \\
\text { HR }(95 \% \\
\mathrm{Cl})\end{array}$ & $p$ \\
\hline \multirow[t]{2}{*}{ BCLC } & A & 1 & 0.055 & & \\
\hline & $\mathrm{B}$ or $\mathrm{C}$ & $2.002(0.986-4.066)$ & & & \\
\hline Previous & None & 1 & 0.020 & 1 & 0.091 \\
\hline \multirow[t]{3}{*}{ C-TACE } & & $2.341(1.141-5.011)$ & & 1.897 & \\
\hline & & & & $(0.9042-4$ & \\
\hline & & & & 161) & \\
\hline \multirow[t]{4}{*}{ Max size } & $<2 \mathrm{~cm}$ & 1 & 0.021 & 1 & 0.0839 \\
\hline & $>2 \mathrm{~cm}$ & $2.450(1.142-5.715)$ & & 2.040 & \\
\hline & & & & $(0.9110-4$ & \\
\hline & & & & 927) & \\
\hline \multirow[t]{3}{*}{ Tumor } & Number < & 1 & 0.158 & & \\
\hline & 3 & $1.674(0.814-3.376)$ & & & \\
\hline & more & & & & \\
\hline
\end{tabular}

B-TACE, balloon-occluded transcatheter arterial chemoembolization with

miriplatin; HR, hazard ratio; $\mathrm{Cl}$, confidence interval; HCV, hepatitis C virus;

ECOG PS, Eastern Cooperative Oncology Group Performance Status; AFP,

a-fetoprotein; DCP, des-y-carboxyprothrombin; PVTT (Branch), portal vein

tumor thrombosis in the 2nd or lower branch; BCLC, Barcelona Clinic Liver

Cancer; C-TACE, conventional transcatheter arterial chemoembolization with

epirubicin; Tumor size, maximum diameter of the tumor

progression-free survival on the univariate analysis. Balloon increase might be the same condition in which a sufficient decrease of BOASP could be obtained. In these cases, denser lipiodol accumulation in the target HCCs might be obtained with enough safety margin by using B-TACE. In contrast, balloon decrease might be the same condition in which a sufficient decrease of BOASP could not be obtained, because isolated arteries, the peribiliary plexus, and the interlobar communicating arcade might be involved in the target HCCs and areas treated under balloon occlusion. In balloon decrease cases, dense lipiodol accumulation might not be obtained using B-TACE [25]. Balloon decrease cases might not be good candidates for B-TACE. In the present study, B-TACE was performed for all target HCCs regardless of the change in tumor stain under balloon occlu-

sion. The present progression-free survival rate tended to be lower than that in a previous report [26]. A possible cause might be that balloon decrease cases were treated with BTACE from the beginning of treatment. The other favorable predictors identified on our univariate analysis may be different from those in previous studies. Previous studies analyzed predictors affecting local control; however, we analyzed predictors affecting progression-free survival without both locoregional recurrence and new lesions in the liver. This could be one of the possible causes. Our favorable predictors affecting progression-free survival might indicate that good tumor control could be obtained at an early stage and in naïve cases.

Although a good local control effect of B-TACE has been reported, only 2 studies have examined the survival rate af- 

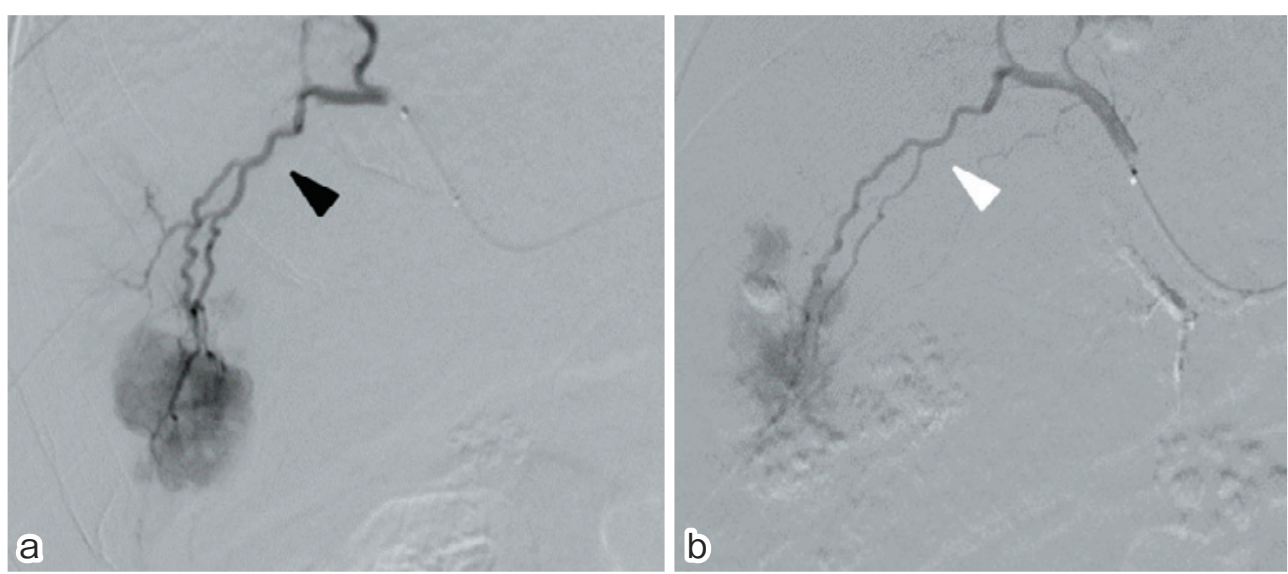

Figure 5. Hepatocellular carcinoma (diameter, $40 \mathrm{~mm}$ ) at hepatic segment $\mathrm{V}$ in a 59-year-old man with hepatitis $\mathbf{C}$ who underwent B-TACE with miriplatin. (a) Selective arteriogram of the anterior branch without balloon occlusion before treatment shows a fine tumor stain and no stenosis in the A5 (arrow head). (b) Selective arteriogram of the anterior branch without balloon occlusion after 3 sessions of B-TACE with miriplatin shows a recurrent tumor stain and no stenosis in the A5 (white arrow head). Therefore, hepatic arterial disease (HAD) was regarded as grade 1 for A5.
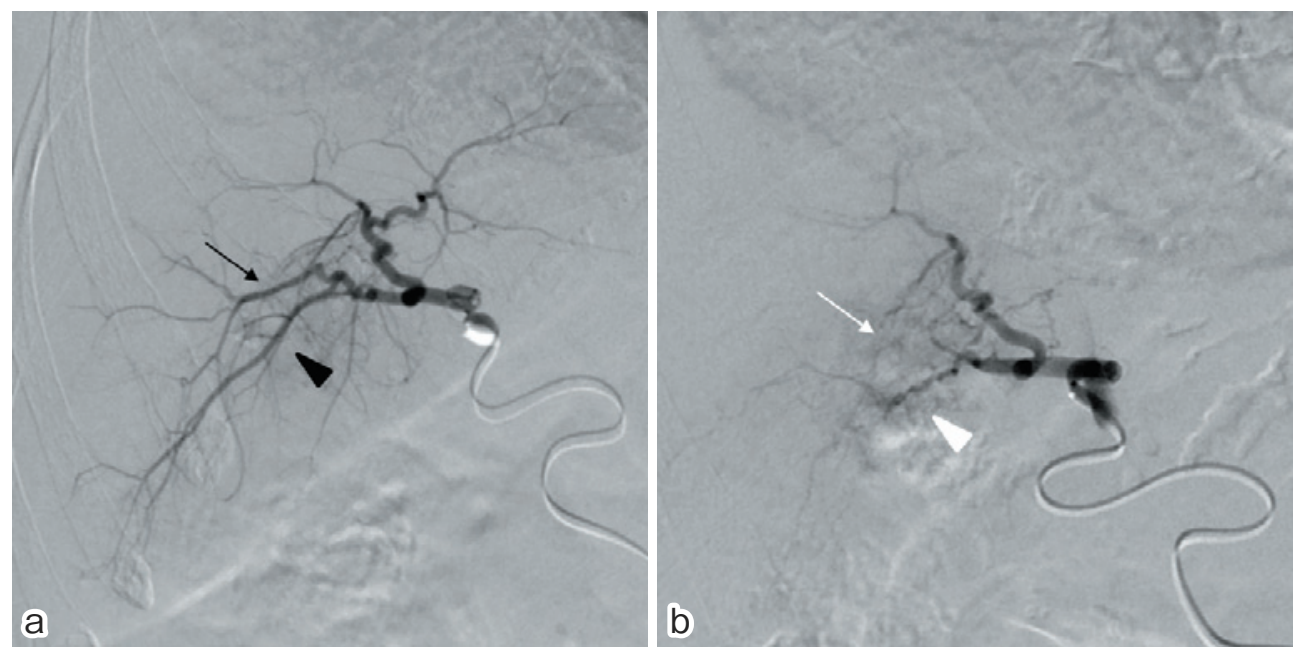

Figure 6. Hepatocellular carcinoma (diameter, $38 \mathrm{~mm}$ ) at hepatic segment VI in an 82-year-old woman with hepatitis $C$ who underwent B-TACE with miriplatin. (a) Selective arteriogram of the posterior branch with balloon occlusion before treatment shows a tumor stain and no stenosis in the A6 (arrow head and arrow). (b) Selective arteriogram of the posterior branch without balloon occlusion after 3 sessions of B-TACE with miriplatin shows a recurrent tumor stain and overt stenosis (white arrow head) and occlusion (white arrow). Therefore, hepatic arterial disease (HAD) was regarded as grade 3 for A6.

ter B-TACE [16-18, 23, 24, 26]. Concerning the survival rate after C-TACE, a Japanese nationwide prospective cohort study reported that the 1-, 3-, 5-, and 7-year survival rates of 8510 patients undergoing C-TACE were $82 \%, 47 \%, 26 \%$, and $16 \%$, respectively [27]. Irie et al. reported that the median survival time was 3.5 years in the 28 patients with 1 or 2 HCC nodules treated using B-TACE with doxorubicin hydrochloride and mitomycin C [26]. Hatanaka et al. reported that the median survival time was 902 days in 66 patients treated using B-TACE with miriplatin [18]. In the present study, the 1-, 2-, and 3-year survival rates were $89.2 \%$, $67.3 \%$, and $60.9 \%$, respectively. The median survival time was 3.6 years after the first B-TACE. The present result appears comparable to those of the above 2 reports regarding $\mathrm{B}-\mathrm{TACE}$ and those of previous reports regarding standard CTACE and DEB-TACE, even though the cohort used in this study had less advanced HCCs [28-32].

In the present study, balloon increase of the largest tumors was the only factor significantly associated with overall survival on the multivariate analysis and the favorable factor significantly associated with progression-free survival on the univariate analysis. Previous studies of C-TACE reported that overall response is an independent prognostic factor for the survival of patients with HCC [33, 34]. 
Table 4. Adverse events after TACE classified according to the CTCAE ver. 4.0

\begin{tabular}{ccccc}
\hline & All Grade (\%) & Grade 1 & Grade 2 & Grade 3 \\
\hline Pain & 21.6 & 8 & 0 & 0 \\
Nausea, Vomiting & 10.8 & 4 & 0 & 0 \\
Fever & 27.0 & 10 & 0 & 0 \\
Leucopenia & 0 & 0 & 0 & 0 \\
Ascites & 5.4 & 2 & 0 & 0 \\
Thrombocytopenia & 5.4 & 2 & 0 & 0 \\
Cholangitis & 5.4 & 0 & 2 & 0 \\
Elevated AST, ALT & 40.5 & 15 & 2 & 0 \\
Elevated Bilirubin & 32.4 & 12 & 0 & 0 \\
\hline
\end{tabular}

Note: The number of cases categorized as each grade according to the National

Cancer Institute's Common Terminology Criteria for Adverse Events (CTCAE

ver. 4.0). TACE, transcatheter arterial chemoembolization; AST, aspartate

aminotransferase; ALT, alanine aminotransferase

Hatanaka et al. also reported that overall response is an independent prognostic factor for the survival of patients with HCC undergoing B-TACE [18]. The largest tumors in the cases presenting balloon increase could be treated more effectively than in those presenting balloon decrease. Therefore, vascular damage and adverse events tended to be fewer and milder in balloon increase cases than in balloon decrease cases, even though we had no clear evidence. Therefore, we could obtain better local control, fewer adverse events, and better overall survival in the balloon increase cases. Moreover, balloon increase of the largest tumors might be the favorable factor significantly associated with overall survival. Other tumor and patient characteristics were not significant predictors of survival after B-TACE, because of the miscellaneous and limited number of patients included in this study. Whether B-TACE results in better survival than does C-TACE should be investigated in the future.

With regard to the adverse events of B-TACE, no significant differences were observed in the effects on hepatic function between B-TACE and C-TACE with miriplatin, thereby indicating that B-TACE is at least as safe as CTACE [7]. Miriplatin causes a lesser degree of vasculitis [15] and slowly releases drugs within the nodule for months [35]. Miriplatin is an anticancer agent that produces less vascular disease, including the narrowing of vessels and shunt formation, and remains only transiently in the vessels surrounding the tumor vessels, and thus has no major side effects [36-38]. However, the rate of vascular damage obtained in this study after B-TACE with miriplatin might be slightly higher than those in previous reports regarding $\mathrm{C}$ TACE with epirubicin and cisplatin [20, 39]. We could not prove the lesser degree of vascular damage caused by miriplatin in this study. The possible causes might be the mechanical stress of balloon inflation and forceful injection of drug and gelatin sponge to the feeding arteries under high pressure. B-TACE induced dense accumulation of anticancer drug and lipiodol in the target HCCs and larger embolized volumes of the normal liver than those induced using superselective TACE; moreover, B-TACE might entail a risk of severe vascular damage and liver dysfunction. In the present study, B-TACE induced mild adverse events, even though 2 cases of cholecystitis (grade 2) were encountered. During BTACE, the forceful injection of lipiodol suspension and embolic agents could be performed under balloon occlusion; therefore, lipiodol and embolic agents migrated into the cystic artery via the collateral pathways, thereby causing cholecystitis. Physicians must recognize the risks of non-target embolization, such as cholecystitis, because of the migration of embolic agents into the cystic artery via the collateral pathways. In particular, physicians must identify the cystic artery before treatment and carefully detect the migration of 
lipiodol during B-TACE. Thus, miriplatin might be an acceptable anticancer drug for B-TACE.

This study has some limitations. First, it was a retrospective and single-arm study, and the sample size was fairly small. Second, recurrences after the first B-TACE were treated mainly using B-TACE with miriplatin, but some recurrent HCCs were treated using RFA, and multiple recurrences were treated using DEB-TACE. Third, balloon increase was a favorable prognostic factor for overall survival and progression-free survival in the present study, but balloon increase was evaluated only on selective angiography with balloon occlusion than in that without balloon occlusion. Change in tumor stain on CT during hepatic angiography was not evaluated. Some balloon increase cases might have been balloon decrease cases if the balloon changes were evaluated on CT during hepatic angiography, because of the heterogeneity of the target HCCs. Additionally, in cases with multiple HCCs, we neither evaluated the balloon change of the HCCs other than the largest tumors nor the effect of controlling all of the HCCs on survival after BTACE. To establish predictors and the long-term efficacy of B-TACE with miriplatin for HCC, therefore, more studies and clinical experience with this treatment are needed. Fourth, the antitumor effects of miriplatin might be unclear in this study. The main effect of TACE may be the ischemic effect, and slow drug elution into the necrotic tumor portion where lipiodol is densely retained may not contribute to long-term tumor control. Miyayama et al. reported very frequent tumor recurrence after TACE with miriplatin despite dense lipiodol accumulation in the tumor on CT performed 1 week after TACE. Miyayama et al. also reported that intratumoral recurrence was more frequent after C-TACE with miriplatin than after C-TACE with epirubicin, because of the high viscosity of miriplatin and incomplete TACE [15]. The strength of B-TACE in this study might be the forceful injection of the miriplatin-lipiodol suspension followed by gelatin sponge particles adequately into the treated arteries under balloon occlusion.

In conclusion, B-TACE with miriplatin was associated with an acceptable survival rate and a low rate of postembolic syndrome. Balloon increase was the only factor significantly associated with overall survival on the multivariate analysis. These results are encouraging, but firm conclusions cannot be drawn because of the small number of patients studied.

Conflict of Interest: We have no direct or indirect financial interest in the products under investigation or subject matter discussed in this manuscript.

\section{References}

1. Bosch FX, Ribes J, Díaz M, Cléries R. Primary liver cancer: worldwide incidence and trends. Gastroenterology. 2004; 127: S516.

2. Llovet JM, Burroughs A, Bruix J. Hepatocellular carcinoma. Lancet. 2003; 362: 1907-1917.
3. de Lope CR, Tremosini S, Forner A, Reig M, Bruix J. Management of HCC. J Hepatol. 2012; 56 (Suppl 1): S75-87.

4. EASL-EORTC clinical practice guidelines: Management of hepatocellular carcinoma. J Hepatol. 2012; 56: 908-943.

5. Facciorusso A, Licinio R, Muscatiello N, Di Leo A, Barone M. Transarterial chemoembolization: Evidences from the literature and applications in hepatocellular carcinoma patients. World $\mathrm{J} \mathrm{He}-$ patol. 2015; 7: 2009-2019.

6. Yamada R, Sato M, Kawabata M, Nakatsuka H, Nakamura K, Takashima S. Hepatic artery embolization in 120 patients with unresectable hepatoma. Radiology. 1983; 148: 397-401.

7. Uchida H, Ohishi H, Matsuo N, Nishimine K, Ohue S, Nishimura $\mathrm{Y}$, et al. Transcatheter hepatic segmental arterial embolization using lipiodol mixed with an anticancer drug and Gelfoam particles for hepatocellular carcinoma. Cardiovasc Intervent Radiol. 1990; 13: $140-145$.

8. Matsui O, Kadoya M, Yoshikawa J, Gabata T, Arai K, Demachi H, et al. Small hepatocellular carcinoma: treatment with subsegmental transcatheter arterial embolization. Radiology. 1993; 188: 79-83.

9. Miyayama S, Matsui O, Yamashiro M, Ryu Y, Kaito K, Ozaki K, et al. Ultraselective transcatheter arterial chemoembolization with a 2-F tip microcatheter for small hepatocellular carcinomas: relationship between local tumor recurrence and visualization of the portal vein with iodized oil. J Vasc Interv Radiol. 2007; 18: 365376.

10. Irie $\mathrm{T}$, Kuramochi M, Takahashi N. Improved accumulation of lipiodol under balloon-occluded transarterial chemoembolization (B-TACE) for hepatocellular carcinoma: measurement of blood pressure at the embolized artery before and after balloon inflation. Jpn J Intervent Radiol. 2009; 26: 49-54.

11. Irie $T$, Kuramochi $M$, Takahashi $N$. Dense accumulation of lipiodol emulsion in hepatocellular carcinoma nodule during selective balloon-occluded transarterial chemoembolization: measurement of balloon-occluded arterial stump pressure. Cardiovasc Intervent Radiol. 2013; 36(3): 706-713.

12. Hamada M, Baba A, Tsutsumishita $Y$, Noguchi T, Yamaoka T, Chiba $\mathrm{N}$, et al. Intra-hepatic arterial administration with miriplatin suspended in an oily lymphographic agent inhibits the growth of tumors in planted in rat livers by including platinum-DNA adducts to form and massive apoptosis. Cancer Chemother Pharmacol. 2009; 64: 473-483.

13. Ikeda K, Okusaka T, Ikeda M, Morimoto M. Transcatheter arterial chemoembolization with a lipophilic platinum complex SM-11335 (miriplatin hydrate)-safety and efficacy in combination with embolizing agents. Jpn J Cancer Chemother. 2010; 37: 271-275 (in Japanese).

14. Oguro S, Hashimoto $S$, Tanaka $T$, Inoue $M$, Nakatsuka $S$, Kuribayashi S, et al. Short-term therapeutic effects of transcatheter arterial chemoembolization using miriplatin-lipiodol suspension for hepatocellular carcinoma. Jpn J Radiol. 2012; 30(9): 735-742.

15. Miyayama S, Yamashiro M, Shibata Y, Hashimoto M, Yoshida M, Tsuji K, et al. Comparison of local control effects of superselective transcatheter arterial chemoembolization using epirubicin plus mitomycin C and miriplatin for hepatocellular carcinoma. Jpn J Radiol. 2012; 30(3): 263-270.

16. Arai H, Abe T, Takayama H, Toyoda M, Ueno T, Kakizaki S, et al. Safety and efficacy of balloon-occluded transcatheter arterial chemoembolization using miriplatin for hepatocellular carcinoma. Hepatol Res. 2015; 45: 663-666.

17. Ogawa M, Takayasu K, Hirayama M, Miura T, Shiozawa K, Abe $\mathrm{M}$, et al. Efficacy of a microballoon catheter in transarterial 
chemoembolization of hepatocellular carcinoma using miriplatin, a lipophilic anticancer drug: short-term results. Hepatol Res. 2016; 46: E60-69.

18. Hatanaka T, Arai H, Shibasaki M, Tojima H, Takizawa D, Toyoda $\mathrm{M}$, et al. Factors predicting the overall response and overall survival in hepatocellular carcinoma patients undergoing balloonoccluded transcatheter arterial chemoembolization (B-TACE): A retrospective cohort study. Hepatol Res. 2017 doi: 10.1111/ hepr.12912

19. Kudo M, Matsui O, Izumi N, Kadoya M, Okusaka T, Miyayama $\mathrm{S}$, et al. Transarterial chemoembolization failure/refractoriness: JSH-LCSGJ criteria 2014 update. Oncology. 2014; 87 Suppl 1: 22-31.

20. Maeda N, Osuga K, Mikami K, Higashihara H, Onishi H, Nakaya $\mathrm{Y}$, et al. Angiographic evaluation of hepatic arterial damage after transarterial chemoembolization for hepatocellular carcinoma. Radiat Med. 2008; 26(4): 206-212.

21. Llovet JM, Bruix J. Systematic review of randomized trials for unresectable hepatocellular carcinoma: chemoembolization improves survival. Hepatology. 2003; 37: 429-442.

22. Camma C, Schepis F, Orlando A, Albanese M, Shahied L, Trevisani $\mathrm{F}$, et al. Transarterial chemoembolization for unresectable hepatocellular carcinoma: meta-analysis of randomized controlled trials. Radiology. 2002; 224: 47-54.

23. Kawamura Y, Ikeda K, Fujiyama S, Hosaka T, Kobayashi M, Saitoh $\mathrm{S}$, et al. Usefulness and limitations of balloon-occluded transcatheter arterial chemoembolization using miriplatin for patients with four or fewer hepatocellular carcinoma nodules. Hepatol Res. 2017; 47(4): 338-346.

24. Ishikawa $\mathrm{T}$, Abe $\mathrm{S}$, Inoue $\mathrm{R}$, Sugano $\mathrm{T}$, Watanabe $\mathrm{Y}$, Iwanaga $\mathrm{A}$, et al. Predictive factor of local recurrence after balloon-occluded TACE with miriplatin (MPT) in hepatocellular carcinoma. PLoS One. 2014; 9: e103009.

25. Asayama Y, Nishie A, Ishigami K, Ushijima Y, Takayama Y, Honda $\mathrm{H}$, et al. Hemodynamic changes under balloon occlusion of hepatic artery: predictor of the short-term therapeutic effect of balloon-occluded transcatheter arterial chemolipiodolization using miriplatin for hepatocellular carcinoma. Springerplus. 2016; 5: 157.

26. Irie $T$, Kuramochi $M$, Kamoshida $T$, Takahashi N. Selective balloon-occluded transarterial chemoembolization for patients with one or two hepatocellular carcinoma nodules: Retrospective comparison with conventional super-selective TACE. Hepatol Res. 2016; 46(2): 209-214.

27. Takayasu K, Arii S, Ikai I, Omata M, Okita K, Ichida T, et al. Prospective cohort study of transarterial chemoembolization for unresectable hepatocellular carcinoma in 8510 patients. Gastroenterology. 2006; 131: 461-469.

28. Yamakado K, Miyayama S, Hirota S, Mizunuma K, Nakamura K, Inaba Y, et al. Subgrouping of intermediate-stage (BCLC stage B) hepatocellular carcinoma based on tumor number and size and
Child-Pugh grade correlated with prognosis after transarterial chemoembolization. Jpn J Radiol. 2014; 32: 260-265.

29. Yamakado K, Miyayama S, Hirota S, Mizunuma K, Nakamura K, Inaba $\mathrm{Y}$ et al. Prognosis of patients with intermediate-stage hepatocellular carcinomas based on the Child-Pugh score: subclassifying the intermediate stage (Barcelona Clinic Liver Cancer stage B) Jpn J Radiol. 2014; 32: 644-649.

30. Ikeda M, Arai Y, Park SJ, Takeuchi Y, Anai H, Kim JK, et al. Prospective study of transcatheter arterial chemoembolization for unresectable hepatocellular carcinoma: an Asian cooperative study between Japan and Korea. J Vasc Interv Radiol. 2013; 24(4): 490500 .

31. Ikeda M, Kudo M, Aikata H, Nagamatsu H, Ishii H, Yokosuka O, et al. Transarterial chemoembolization with miriplatin vs. epirubicin for unresectable hepatocellular carcinoma: a phase III randomized trial. J Gastroenterol. 2017 [Epub ahead of print]

32. Golfieri R, Giampalma E, Renzulli M, Cioni R, Bargellini I, Bartolozzi C, et al. Randomised controlled trial of doxorubicin-eluting beads vs conventional chemoembolisation for hepatocellular carcinoma. Br J Cancer. 2014; 111(2): 255-264.

33. Gillmore R, Stuart S, Kirkwood A, Hameeduddin A, Woodward $\mathrm{N}$, Burroughs AK, et al. EASL and mRECIST responses are independent prognostic factors for survival in hepatocellular cancer patients treated with transarterial embolization. J Hepatol. 2011; 55: 1309-1316.

34. Shim JH, Lee HC, Kim SO, Shin YM, Kim KM, Lim YS, et al. Which response criteria best help predict survival of patients with hepatocellular carcinoma following chemoembolization? A validation study of old and new models. Radiology. 2012; 262: 708-718.

35. Kishimoto S, Noguchi T, Yamaoka T, Fukushima S, Takeuchi Y. In vitro release of SM-11355, (1R,2R)-1,2- Cyclohexanediamine-N, N7) bis(myristato)] Platium (II) suspended in lipiodol. Biol Pharm Bull. 2000; 23: 637-640.

36. Fujiyama S, Shibata J, Maeda S, Tanaka M, Noumaru S, Sato K, et al. Phase I clinical study of a novel lipophilic platinum complex (SM-11 355) in patients with hepatocellular carcinoma refractory to cisplatin/lipiodol. Br J Cancer. 2003; 89: 1614-1619.

37. Okusaka T, Okada S, Nakanishi T, Fujiyama S, Kubo Y. Phase II trial of intra-arterial chemotherapy using a novel lipophilic platinum derivative (SM-11 355) in patients with hepatocellular carcinoma. Invest New Drugs. 2004; 22: 169-176.

38. Kamimura K, Suda T, Tamura $Y$, Takamura M, Yokoo T, Igarashi $\mathrm{M}$, et al. Phase I study of miriplatin combined with transarterial chemotherapy using CDDP powder in patients with hepatocellular carcinoma. BMC Gastroenterol. 2012; 12: 127.

39. Suh CH, Shin JH, Yoon HM, Yoon HK, Ko GY, Gwon DI, et al. Angiographic evaluation of hepatic arterial injury after cisplatin and Gelfoam-based transcatheter arterial chemoembolization for hepatocellular carcinoma in a 205 patient cohort during a 6-year follow-up. Br J Radiol. 2014; 87(1041): 20140054. 